\title{
THE EFFECT OF THERMOMECHANICAL PROCESSING ON THE MICROSTRUCTURE AND CREEP BEHAVIOR OF UDIMET ALLOY 188
}

\author{
S.C. Longanbach and C.J. Boehlert \\ Department of Chemical Engineering and Materials Science, Michigan State University, 2527 Engineering Building, East Lansing, MI \\ 48824, U.S.A.
}

Keywords: Cobalt-based alloy, Electron backscatter diffraction, Creep, Microstructure

\begin{abstract}
Udimet 188 alloy was subjected to thermomechanical processing in attempt to understand the effects of cold-rolling deformation on the microstructure and tensile-creep behavior. Commercially available sheet was cold rolled to varying amounts of deformation (between 5\%-35\% reduction in sheet thickness) followed by a solution treatment at $1191^{\circ} \mathrm{C}$ for one hour followed by air cooling. This sequence was repeated four times to induce a favorable grain boundary character distribution containing a high volume fraction of low-energy grain boundaries. The resultant microstructure was characterized using electron backscattered diffraction. The effect of the thermomechanical processing treatment on the hightemperature $\left(760-815^{\circ} \mathrm{C}\right)$ creep behavior was evaluated. Conventional lever-arm creep experiments were performed in an open air environment. The measured creep stress exponents (5.76.4) suggested that dislocation creep was dominant at $760^{\circ} \mathrm{C}$ for stresses ranging between 100-220MPa. The material exhibited a significant extent of grain boundary cracking. The thermomechanical processing treatments which resulted in the greatest fractions $(\sim 0.8)$ of special grain boundaries (low-angle boundaries + coincident site lattice boundaries) also exhibited the lowest creep rates. Thus a correlation was exhibited between the grain boundary character distribution and the minimum creep rates. Creep rupture experiments were performed at $\mathrm{T}=815^{\circ} \mathrm{C}$ and $\sigma=165 \mathrm{MPa}$ and the thermomechanical processing treatment which resulted in the greatest special boundary fraction also resulted in the greatest average time-to-rupture.
\end{abstract}

\section{Introduction}

The development of superior-strength materials used in hightemperature applications is necessary for the continued improvement of turbine-engine systems. Udimet alloy 188 (also known as Haynes Alloy No. 188) is a commercially available cobalt-nickel-chromium-tungsten alloy with good creep strength and oxidation resistance up to $1093^{\circ} \mathrm{C}$. The alloy also has good fabricability, tensile strength and elongation-to-failure $\left(\varepsilon_{\mathrm{f}}\right)$, weldability, low-cycle fatigue resistance, and corrosion resistance [1-6]. Despite its use in gas turbines, combustors, flame holders, liners, and transition ducts, only a limited number of studies have examined how processing affects the microstructure and creep behavior of Udimet alloy 188 [4,5,7,8].

Klarstom [7] found that strongly textured recrystallized sheets gave a significant improvement in the low-strain creep strength over baseline untextured sheets. The thermomechanical processing (TMP) that gave optimum results consisted of $80 \%$ final cold work followed by an anneal at $1232^{\circ} \mathrm{C}$ for 10 minutes. The major components of the texture resulting from this thermomechanical processing (TMP) schedule, with respect to the plane of the sheet and the rolling direction, were identified as (110) [-110] and (112) [-110]. Typical dislocation structures in baseline untextured sheets consisted of tangles produced by the intersection and reaction of glide dislocations, and pileups at grain boundaries and relatively large carbide particles. Whittenberger $[4,5]$ found that the measurable changes in the creep behavior of Udimet alloy 188 are ascribable to thermal aging effects rather than corrosion in air or $\mathrm{LiF}-22 \mathrm{CaF}_{2}$ environments. From these studies it is evident that a complete understanding of the physical mechanisms responsible for the elevated-temperature creep behavior and associated microstructure-property relationships is lacking. In particular, it has yet to be established if this alloy can be TMP to significantly alter the grain boundary character distribution (GBCD: the fraction of each type of boundary found in a microstructure), which has proven to have a significant influence on the mechanical deformation, creep behavior, and corrosion resistance of other fcc-based superalloy systems [9-25]. Thus, there is the potential to improve performance using grain boundary engineering strategies.

Grain boundary engineering, as described by Watanabe [26], is the process of altering the GBCD through TMP. The types of boundaries are characterized as general high-angle boundaries (GHAB: greater than $15^{\circ}$ misorientation), low-angle boundaries (LAB: less than $15^{\circ}$ misorientation), and coincident site lattice boundaries (CSLB or $\Sigma$, where the reciprocal of the fraction of coincident sites between two grains at the grain boundary is noted; for example a twin boundary has $1 / 3$ coincident sites and is denoted as $\Sigma 3$ ). The GBCD is related to the spatial configuration of these boundaries and the connectivity of the boundary network $[10,21,27]$. Lehockey and Palumbo [20] have shown that a high fraction of LAB+CSLB (termed special boundaries) significantly enhances resistance to creep of pure nickel at elevated temperature. In their study, voids and cavitations appeared almost exclusively along GHAB.

This work was intended to evaluate processing-microstructureproperty relationships of Udimet alloy 188. In particular the effect of cyclic cold rolling on the microstructure and hightemperature creep behavior was evaluated. The overall goal was to change the grain boundary structure in a manner that would improve the minimum creep rates and increase the creep rupture life.

\section{Experimental}

There are at least two different methods employed for altering GBCD. The first method requires moderate strain levels ( 30\%) followed by short high-temperature anneals [10,21,27]. The second method involves the imposition of small strain increments, 
$6-8 \%$, followed by annealing to initiate grain boundary migration and the realization of lower energy boundaries [28]. In this work, both small and large strain increments were imposed on Udimet alloy 188 sheets followed by an identical annealing treatment. The TMP schemes are shown in Table I. In particular, Sheets A and $\mathrm{B}$ were subjected to cold rolling deformations of $5 \%$ and $15 \%$, respectively, while Sheets C and D were subjected to $35 \%$ cold rolling. The only difference between Sheets C and D were the fourth cold rolling deformation cycle which was $10 \%$ for Sheet C and $25 \%$ for Sheet D. After each cold rolling sequence a heat treatment at $1191^{\circ} \mathrm{C}$ for one hour was performed. Based on previous observations [6] this heat treatment would provide full recrystallization of the worked microstructure.

Table I. Thermomechanical Processing Sequences

\begin{tabular}{|c|c|}
\hline Sheet & TMP Sequence \\
\hline A & $5 \% \mathrm{CW}, 5 \% \mathrm{CW}, 5 \% \mathrm{CW}, 5 \% \mathrm{CW}$ \\
\hline B & $15 \% \mathrm{CW}, 15 \% \mathrm{CW}, 15 \% \mathrm{CW}, 15 \% \mathrm{CW}$ \\
\hline $\mathrm{C}$ & $35 \% \mathrm{CW}, 35 \% \mathrm{CW}, 35 \% \mathrm{CW}, 10 \% \mathrm{CW}$ \\
\hline $\mathrm{D}$ & $35 \% \mathrm{CW}, 35 \% \mathrm{CW}, 35 \% \mathrm{CW}, 25 \% \mathrm{CW}$ \\
\hline
\end{tabular}

CW - cold work

Each TMP sheet was sectioned and metallographically polished before spatially resolved EBSD orientation maps were obtained using hardware and software manufactured by EDAX-TSL, Inc (Mahwah, NJ). The specimens were ground mechanically using $15 \mu \mathrm{m}, 6 \mu \mathrm{m}$ and $1 \mu \mathrm{m}$ diamond suspension for 20 minutes, respectively, and then polished using $0.06 \mu \mathrm{m}$ colloidal silica. The step size used to obtain the EBSD orientation maps ranged between $0.5-2 \mu \mathrm{m}$ and over 500 grains were analyzed per orientation map. The GBCD was assessed with LAB defined as having 2-15 degrees of misorientation. Brandon's criterion [29] was used to distinguish between the GHAB and the CSLB. The GBCD were obtained using the measured fractions of GHAB, $\mathrm{LAB}, \mathrm{CSLB}$, and twins $(\Sigma 3)$. These measurements were averaged from several orientation maps, performed on the cross-sections, rolling faces, or longitudinal sections of the TMP sheet materials. The precipitate volume fractions were determined using ImageJ image analysis software on backscattered electron (BSE) scanning electron microscope (SEM) photomicrographs acquired using a CamScan44FE Field Emission SEM. The grain size was determined using the line-intercept method [30,31].

All creep specimens were machined from the TMP sheets into a dogbone geometry using electrical discharge machining (EDM). The tensile axis was parallel to the rolling direction. Creep specimens were mechanically ground to a 600 grit finish to remove the EDM recast layer. Creep and creep rupture experiments were performed in air using constant-load vertical creep frames manufactured by Applied Test Systems, Incorporated; Butler, PA. The creep experiments were performed at a temperature of $760^{\circ} \mathrm{C}$ and stresses between $100-220 \mathrm{MPa}$. Specimen temperatures, which were monitored by three thermocouples within the gage section, were kept within $3^{\circ} \mathrm{C}$ of the target temperature and strain was monitored using a linear variable differential transformer on a $25 \mathrm{~mm}$ gage-length hightemperature extensometer. No extensometer was used for the creep rupture experiments. In addition, two creep rupture experiments were performed at a temperature of $815^{\circ} \mathrm{C}$ at a stress of $165 \mathrm{MPa}$ for each TMP sheet. All specimens were soaked at the creep temperature for at least one hour to establish thermal equilibrium prior to applying the creep load. The tests were conducted such that the time to reach the maximum creep load was five seconds or less and the time, load, temperature, and strain were recorded periodically throughout the experiments. During the creep experiments, after the creep strain had proceeded well into the secondary regime, the load was changed or the creep test was discontinued. In general, 300 hours was sufficient to achieve a steady-state creep rate and thus 300 hours was chosen as the minimum time needed before changing the load. The tested specimens were cooled under load to minimize recovery of the dislocation substructure. After the experiments were terminated, the fracture surfaces of the fractured samples were examined using SEM. In addition, the gage sections of both fractured and unfractured samples were prepared for SEM imaging. It is noted that, Sheet A was creep tested under identical conditions at $760^{\circ} \mathrm{C}$ to evaluate the repeatability of the creep strain-life behavior.

\section{Results and Discussion}

\section{Microstructure}

Table II lists the measured alloy composition. Figure 1a-d illustrates BSE SEM images of the TMP microstructures. The average equiaxed fcc grain size, which excluded twins, ranged from $22-164 \mu \mathrm{m}$ depending on the amount of cold rolling (see Table III). Greater total cold work resulted in finer grain sizes.

Table II. Measured Alloy Composition

\begin{tabular}{|l|l|l|l|l|l|l|l|l|l|}
\hline Co & $\mathrm{Ni}$ & $\mathrm{Cr}$ & $\mathrm{W}$ & $\mathrm{Fe}$ & $\mathrm{Mn}$ & $\mathrm{Si}$ & $\mathrm{Mo}$ & $\mathrm{C}$ & $\mathrm{Al}$ \\
\hline 36.8 & 24.2 & 22.1 & 12.0 & 2.5 & 1.0 & 0.4 & 0.4 & 0.1 & 0.1 \\
\hline
\end{tabular}

All microstructures exhibited a small amount (2-5\%, Table III) of homogeneously-distributed fine spherical precipitates, believed to be $\mathrm{M}_{6} \mathrm{C}$ or $\mathrm{M}_{23} \mathrm{C}_{6}$ carbide precipitates based on previous literature [6]. It is noted that the grain boundaries were intact and not cracked after the TMP.

Figure 2a-d illustrates EBSD data for each TMP sheet. The orientation maps show that the grains were equiaxed and their orientations were distributed fairly evenly. Pole figure analysis indicated that the TMP microstructure was not strongly textured (2.5x random or less for all cases). A significant volume fraction of twins were observed in the microstructures as evident in the orientation maps and in the misorientation histograms. Table III lists the fractions of LAB, GHAB, CSLB, and $\Sigma 3$ boundaries for each TMP microstructure. CSLB held the majority of the grain boundary volume with fractions between 0.51 and 0.77 . The lowest volume fraction of twins (0.43) was exhibited by Sheet D. The maximum fraction of twins, which constituted the vast majority of the CSLB, was 0.65 and 0.62 in the Sheet A and C microstructures, respectively. These sheets also exhibited the greatest fraction of CSLB (0.77 and 0.75) and special boundaries (0.81 and 0.78).

From the statistical percolation physics of 3-D grain boundary engineering, percolation along weak boundaries is possible if the special boundary fraction is less than 0.78 [32]. Thus the ability of a weak boundary to percolate would be expected to diminish as the special boundary fraction approaches this threshold. The Sheets B and D exhibited the lowest special boundary fractions of 0.70 and 0.63 , respectively. 


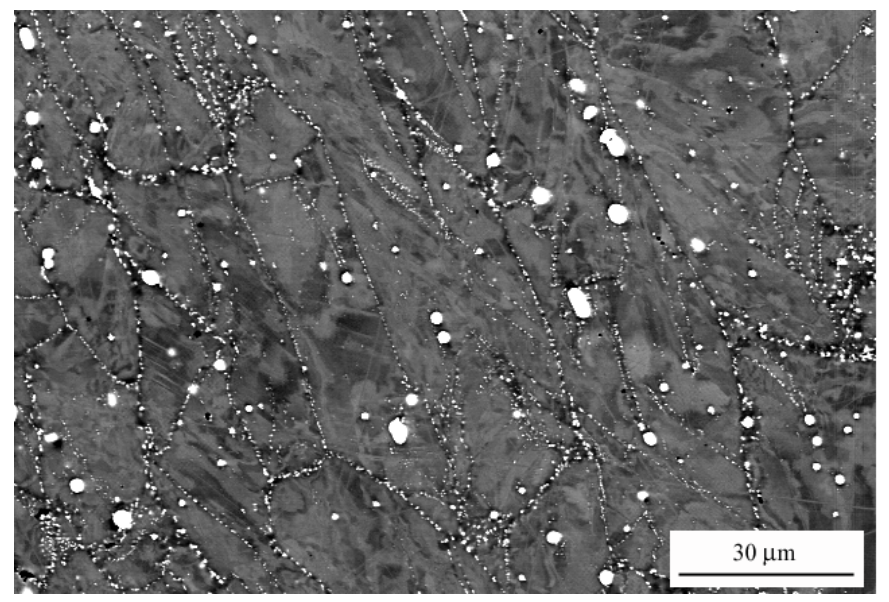

(a)

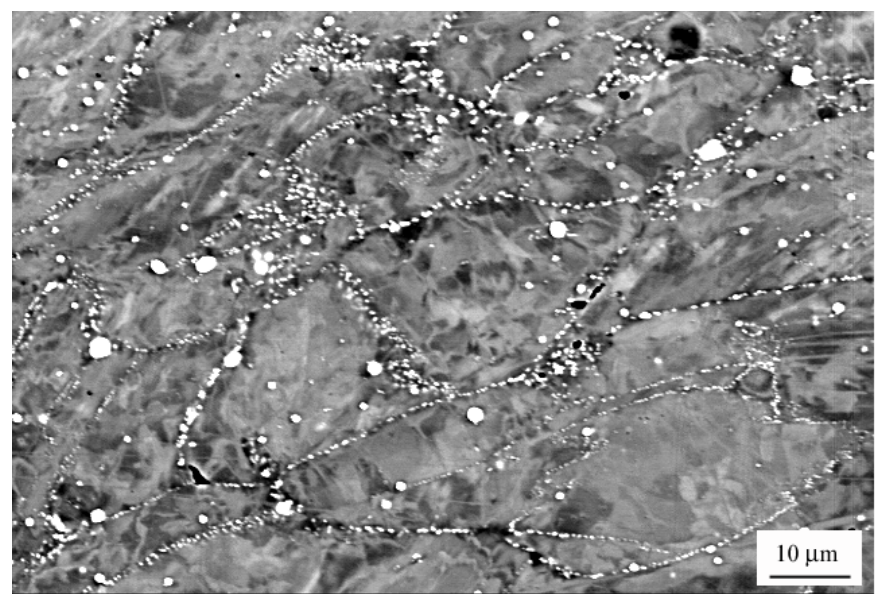

(c)

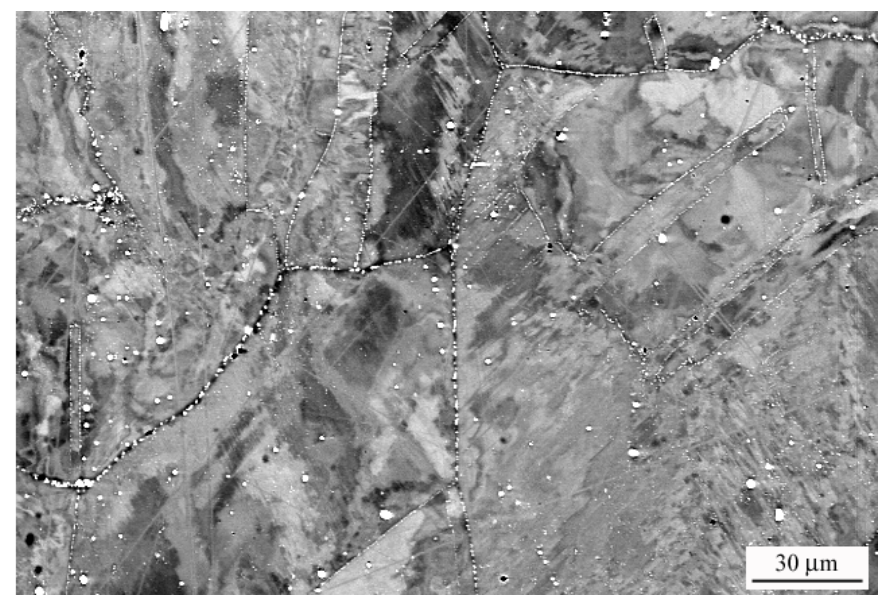

(b)

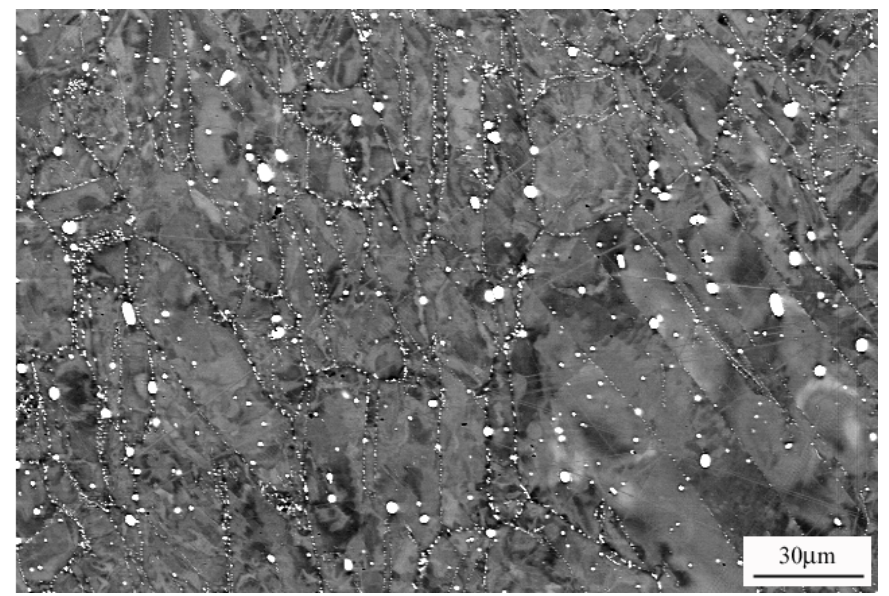

(d)

Figure 1. Backscattered electron SEM images of the microstructures for (a) Sheet A, (b) Sheet B, (c) Sheet C, and (d) Sheet D.

Table III. GBCD Parameters, FCC Grain Sizes and Volume Percents of Precipitates for each TMP sheet

\begin{tabular}{|c|c|c|c|c|c|c|}
\hline Sheet & GHAB & CSLB $(\Sigma 3)$ & LAB & $\begin{array}{c}\text { GS excluding } \\
\text { twins, } \mu \mathrm{m}\end{array}$ & $\begin{array}{c}\text { GS including } \\
\text { twins, } \mu \mathrm{m}\end{array}$ & $\begin{array}{c}\text { Precipitate } \\
\text { Volume Percent }\end{array}$ \\
\hline A & 0.19 & $0.77(0.65)$ & 0.04 & 164 & 36 & \\
\hline B & 0.30 & $0.67(0.59)$ & 0.03 & 147 & 11 & 2.3 \\
\hline C & 0.22 & $0.75(0.62)$ & 0.03 & 76 & 19 & 4.3 \\
\hline D & 0.37 & $0.51(0.43)$ & 0.12 & 22 & 11 & 5.2 \\
\hline
\end{tabular}



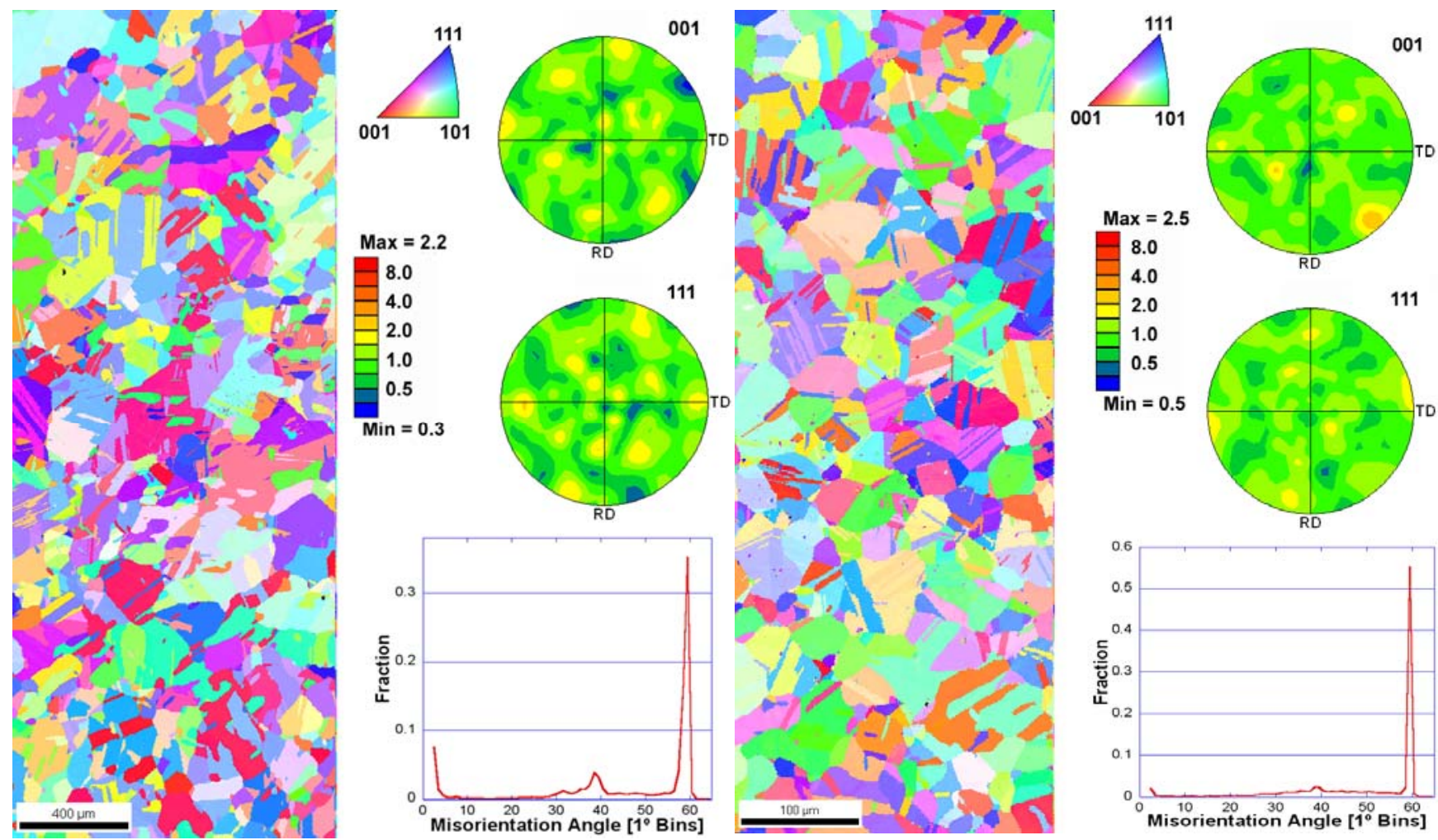

(a)

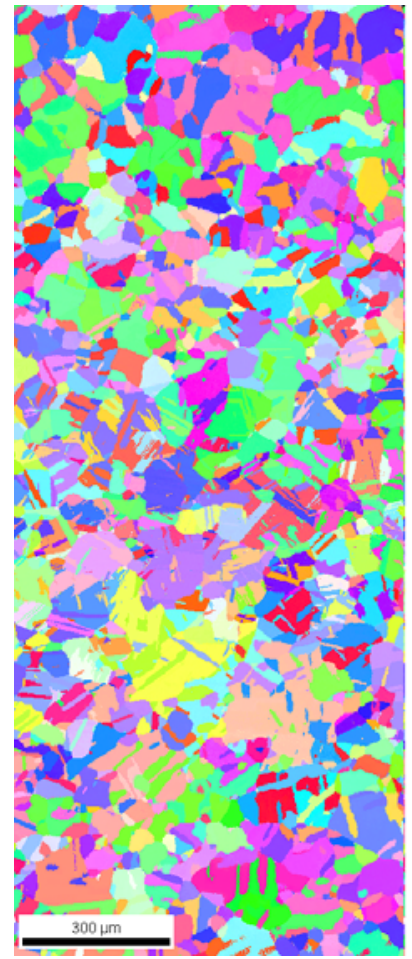

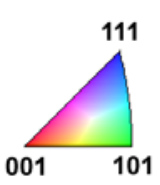
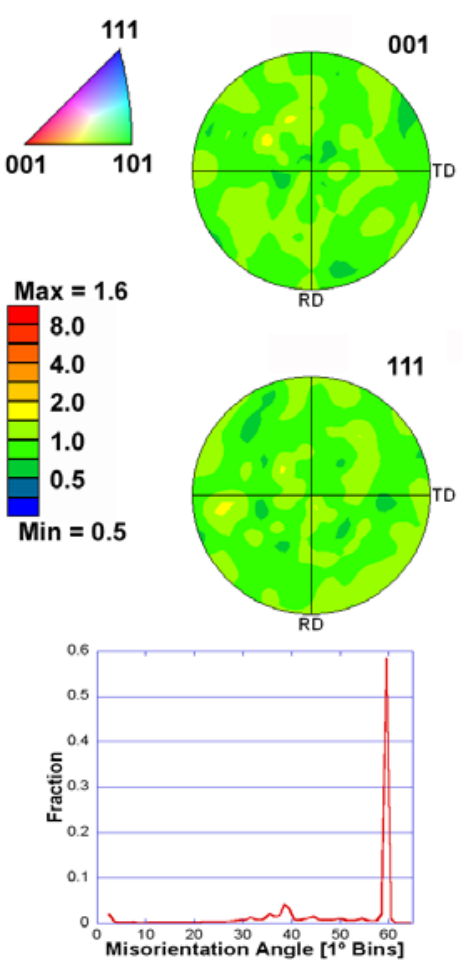

(c)
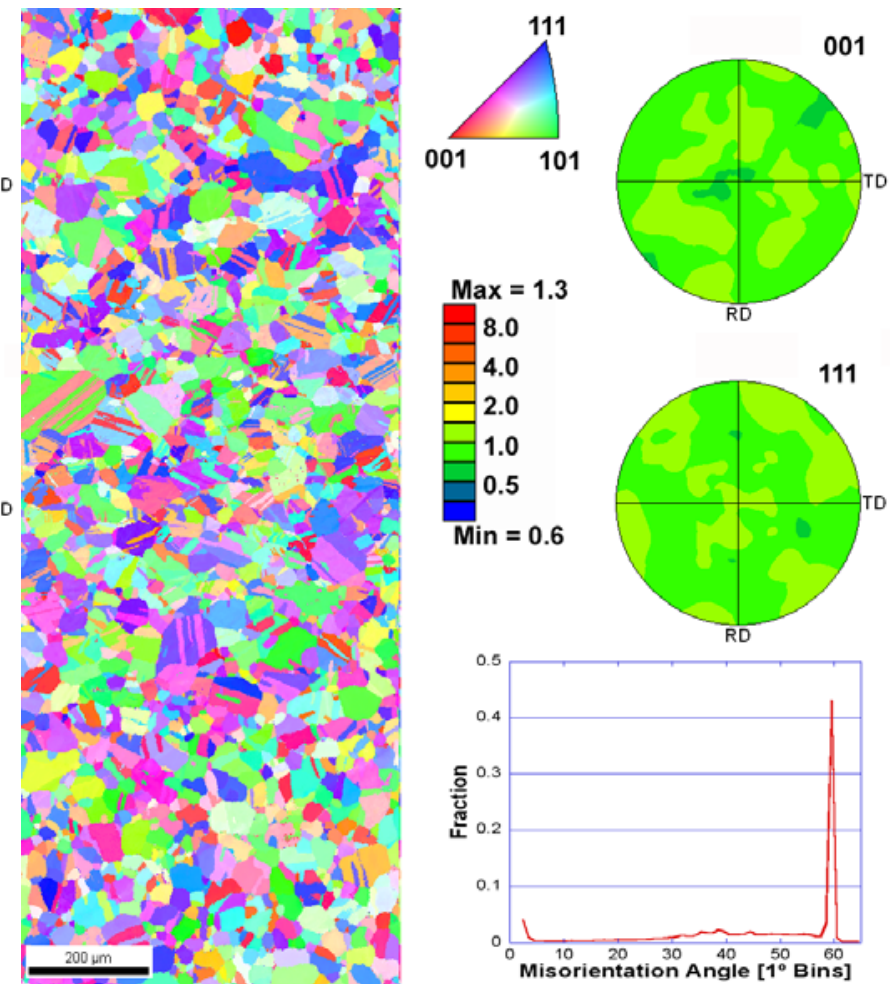

(d)

Figure 2. Orientation maps, pole figures and grain boundary misorientation angle histograms for (a) Sheet A, (b) Sheet B, (c) Sheet C, and (d) Sheet D. 


\section{Creep Behavior}

Creep testing was performed to characterize the creep resistance of each sheet as well as aid in determining the dominant creep mechanism operating under the stress and temperature conditions tested. The creep strain-life history resembled that for most metals exhibiting three stages of creep: primary, secondary and tertiary. Once the creep stress was reached there appeared to be a short incubation period before a positive creep strain was achieved. This was common for each sample tested. The creep strain-life behavior was repeatable as two specimens from Sheet A were tested under identical stresses and temperatures and the strain-life behavior is shown in Figure 3a. For these specimens, the minimum creep rates were averaged and the average values were used for determining the creep stress exponent (n). Figure 3b illustrates creep strain versus time plots for each of the sheets at $\mathrm{T}=760^{\circ} \mathrm{C}$ and $\sigma=100-130 \mathrm{MPa}$ for a load jump experiment. The Sheet $\mathrm{C}$ material exhibited the greatest creep resistance. Sheet D exhibited the poorest creep resistance, while Sheet B exhibited the second-poorest creep resistance.

Figure 4 illustrates a log minimum strain rate versus log stress plot used to calculate the creep exponent $n$. The experimentallydetermined creep exponents fell in the range of 5.7-6.4. Sheets A and $C$ exhibited greater creep resistance than the other sheets at all of the applied stresses evaluated. Thus, similar to that observed for previous work on grain boundary engineered nickel [20], a greater volume of special boundaries corresponded to greater creep resistance. Based on the measured creep exponents, dislocation creep was the suggested dominant creep mechanism over the entire applied stress range examined $(100 \mathrm{MPa}<\sigma<220 \mathrm{MPa})$ independent of the extent of cold rolling deformation. The lower creep resistance of the Sheets B and D corresponded with a lower fraction of special boundaries.

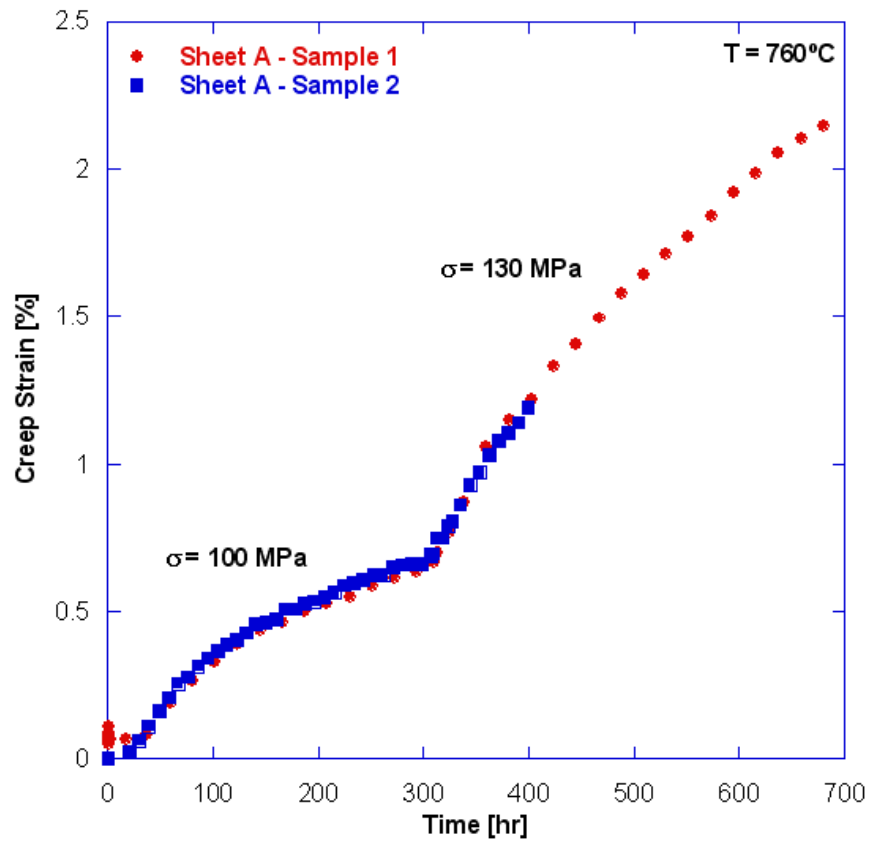

(a)
Creep rupture experiments were performed at $\mathrm{T}=815^{\circ} \mathrm{C}$ and $\sigma=165 \mathrm{MPa}$. The average creep rupture times, provided in Table IV, varied between 83-97 hours. Sheet A exhibited the greatest average creep rupture life. Although some variability existed in the rupture lives, the microstructure with the greatest fraction of special boundaries exhibited the greatest average creep life. Each of the ruptured samples exhibited at least 20\% elongation-tofailure and mixed-mode fracture features were observed on the fracture surfaces. The fracture surfaces of the creep ruptured samples are illustrated in Figure $5 \mathrm{a}$ and $\mathrm{b}$.

Table IV. Creep Rupture Time at $815^{\circ} \mathrm{C} / 165 \mathrm{MPa}$

\begin{tabular}{|c|c|c|}
\hline Sheet & $\mathrm{T}_{\mathrm{r}}[\mathrm{hr}]$ & Average $\mathrm{T}_{\mathrm{r}}[\mathrm{hr}]$ \\
\hline A & 82,111 & 97 \\
\hline B & 51,115 & 83 \\
\hline C & 85,100 & 93 \\
\hline D & 85,103 & 94 \\
\hline
\end{tabular}

These exhibited both ductile (dimples) and brittle fracture (faceting) characteristics. Grain boundary cracking was observed on the ruptured samples both near and away from the fracture surfaces. There were no visible flaws or cracks along the grain boundaries after TMP so the cracks developed due to creep deformation. Figure 6a and b illustrate BSE SEM micrographs of the gage section for Sheet A after a creep-rupture experiment. Figure 7a and b illustrate BSE SEM micrographs of the gage section for Sheet D. Intergranular cracking was exhibited for each of the specimens indicating that this alloy is susceptible to grain boundary deformation. Grain boundary cracking tends to develop on the GHAB for this alloy [33,34]. This may help explain why the material with the lowest fraction of GHAB exhibited the greatest creep resistance. Previous observations have indicated that environmental effects were not the cause of grain boundary cracking [33].

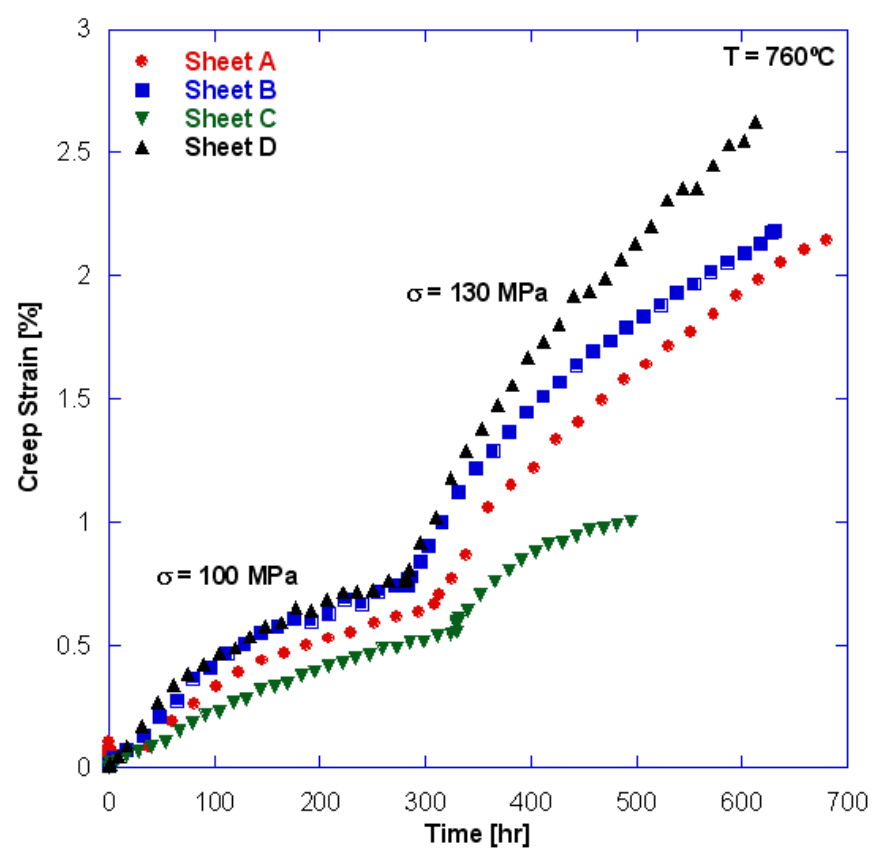

(b)

Figure 3. Comparison creep strain versus time plots taken during from a load jump experiment at $\mathrm{T}=760^{\circ} \mathrm{C}, \sigma=100-130 \mathrm{MPa}$ for $(\mathrm{a})$ two Sheet A samples verifying reproducibility of the strain life behavior and (b) for Sheets A-D specimens. 


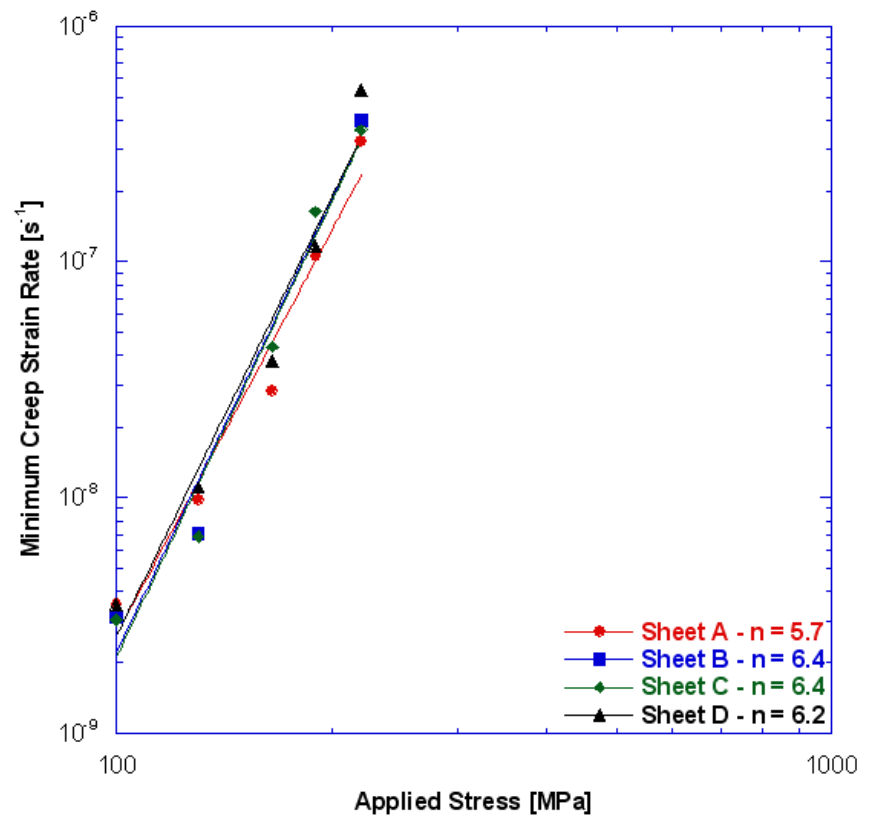

Figure 4. Log minimum creep rate versus applied stress for each of the TMP sheets evaluated. This data was used to calculate the creep stress exponent (n).

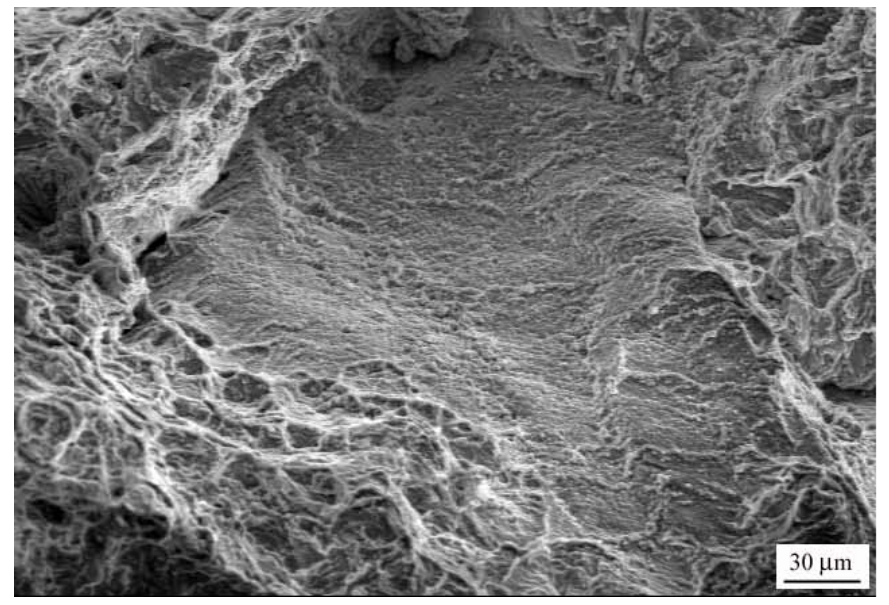

(a)

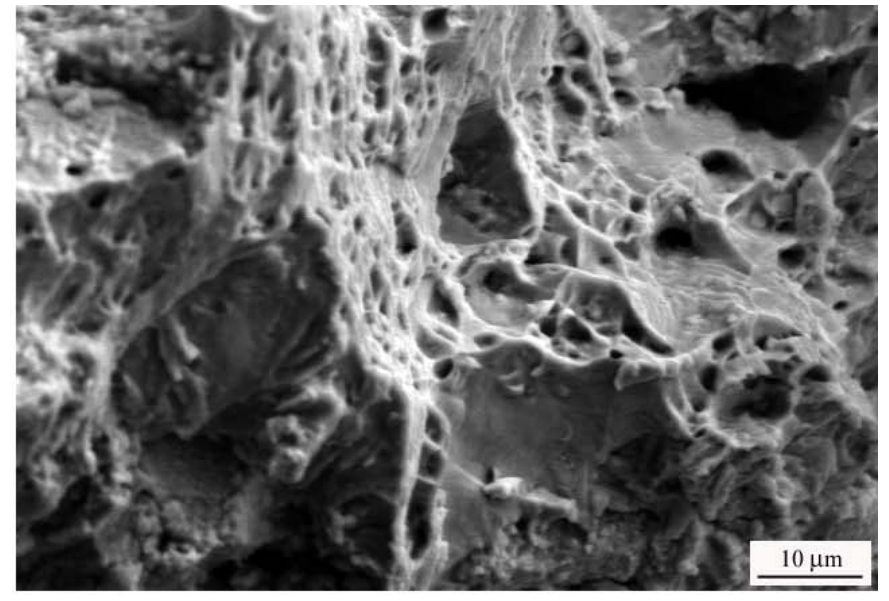

(b)

Figure 5. Secondary electron SEM images for the fracture surfaces of (a) Sheet A and (b) Sheet C creep rupture (815 $\left.{ }^{\circ} \mathrm{C} / 165 \mathrm{MPa}\right)$ specimens. Both exhibited ductile dimpling and cleavage facets. 


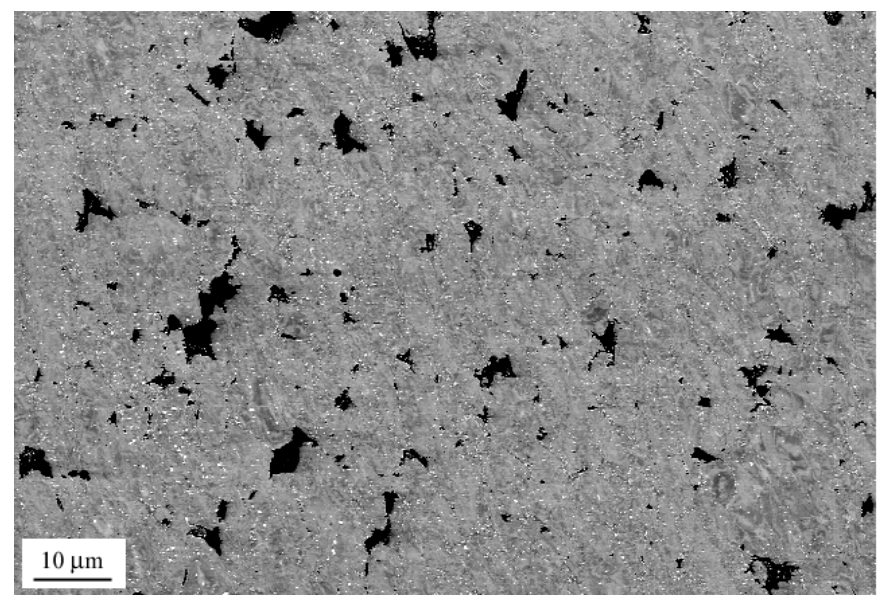

(a)

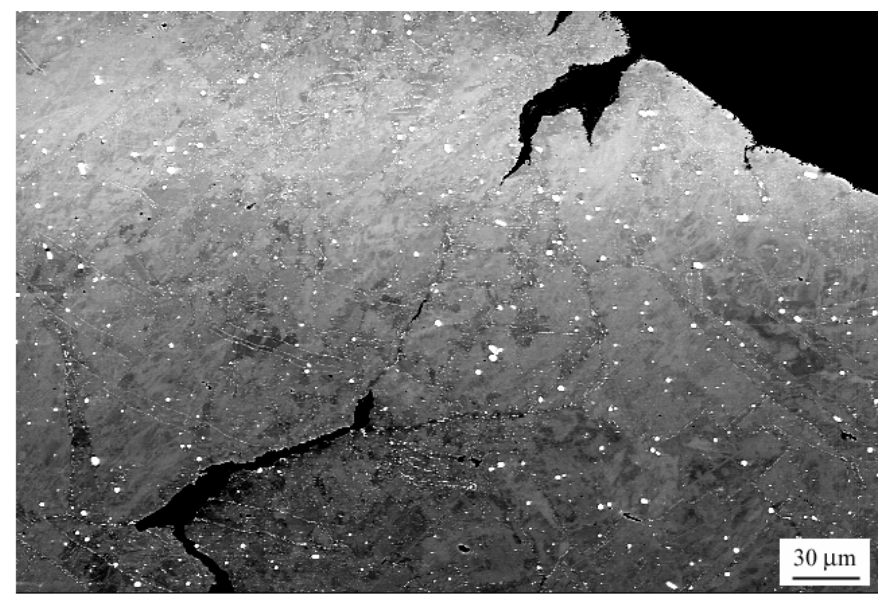

(b)

Figure 6. Backscattered electron SEM images of creep ruptured $\left(815^{\circ} \mathrm{C} / 165 \mathrm{MPa}\right)$ Sheet A samples illustrating (a) grain boundary cracking behind the fracture surface and (b) environmentally-assisted cracking at the surface edge along with an intergranular crack propagating through the sample.

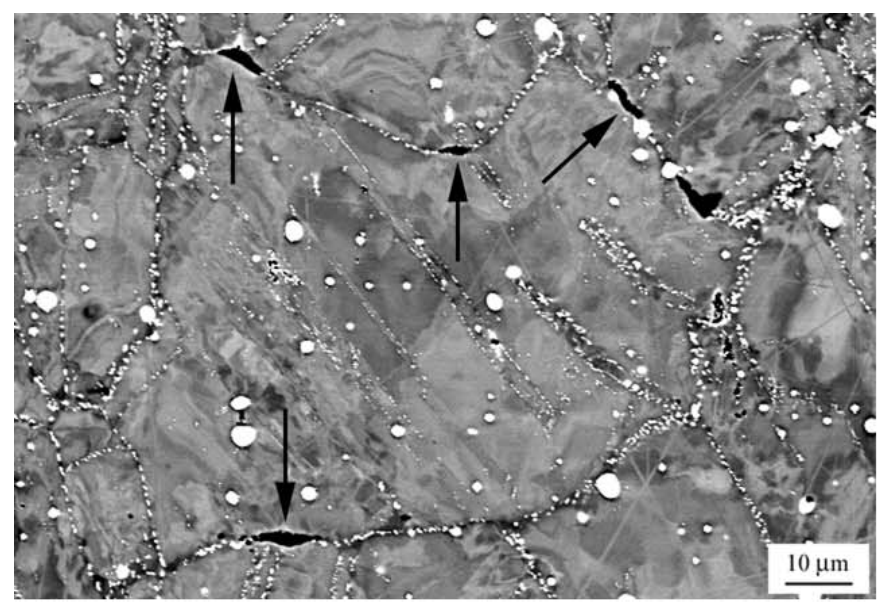

(a)

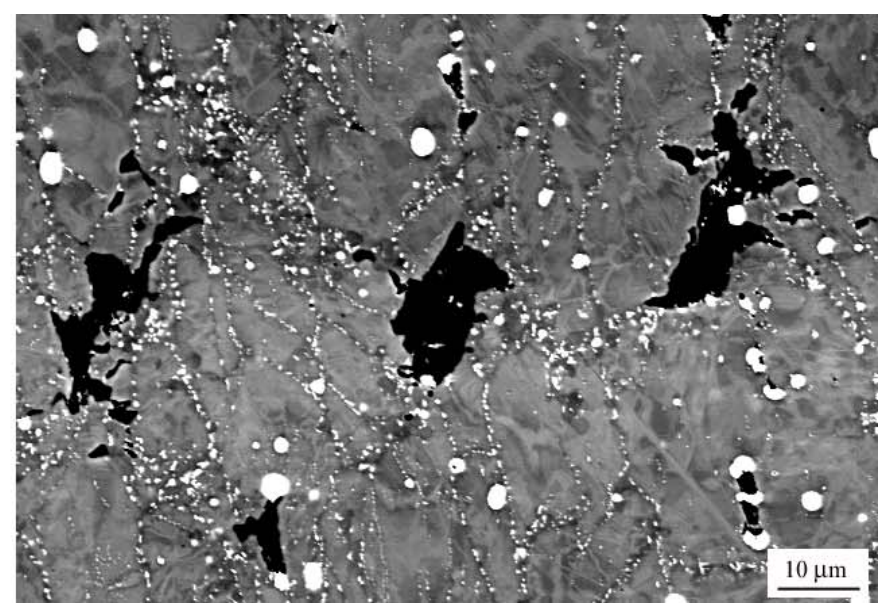

(b)

Figure 7. Backscattered electron SEM images of creep ruptured $\left(815^{\circ} \mathrm{C} / 165 \mathrm{MPa}\right)$ Sheet D demonstrating (a) grain boundary cracking (indicated by arrows) several millimeters away from the fractured surface and (b) cracking within $1 \mathrm{~mm}$ of the fractured surface which tended to occur at the grain boundaries.

\section{Conclusions}

This work evaluated the effect of TMP on the microstructure and creep behavior of Udimet alloy 188. For the applied stresses and temperature evaluated, the measured creep exponents suggested that dislocation creep was the dominant creep deformation mechanism independent of the processing condition. This alloy was susceptible to grain boundary cracking during creep deformation for all the processing conditions examined. The thermomechanical processing treatment which resulted in the greatest fractions of special grain boundaries (low-angle boundaries + coincident site lattice boundaries) also exhibited the lowest creep rates and greatest average time-to-rupture. Thus a correlation was exhibited between the grain boundary character distribution and the creep resistance.

\section{Acknowledgments}

This work was supported by the National Science Foundation through grant DMR-0533954. The authors are grateful to Mr. Nathan Eisinger (Special Metals Corporation) for overseeing the alloy processing.

\section{References}

1. C.J. Lissenden, J.F. Colaiuta, B.A. Lerch, "Hardening behavior of three metallic alloys under combined stress at elevated temperature,” Acta Mech., 169 (2004), 5377.

2. D. Zhu, D.S. Fox, and R.A. Miller, “Oxidation and creep-enhanced fatigue of Haynes 188 alloy-oxide system under simulated pulse detonation engine 
conditions,” Ceram. Eng. Sci. Proc., 23.4 (2002), 547553.

3. J. Chen et al., "Tensile hold low-cycle fatigue behavior of cobalt-based HAYNES ${ }^{\circledR} 188$ superalloy,” Scripta Mater., 44 (2001), 859-865.

4. J.D. Whittenberger, "Mechanical properties of Haynes alloy 188 after exposure to $\mathrm{LiF}-22 \mathrm{CaF}_{2}$, air, and vacuum at $1093 \mathrm{~K}$ for periods up to 10,000 hours," J. Mater. Eng. Perf., 1 (4) (1992), 469-482.

5. J.D. Whittenberger, "Mechanical properties of Haynes alloy 188 after 22,500 hours of exposure to $\mathrm{LiF}-22 \mathrm{CaF}_{2}$ and vacuum at 1093K," J. Mater. Eng. Perf., 3 (6) (1994), 754-762.

6. R.B. Herchenroeder et al., "Haynes alloy No. 188," Cobalt, 54 (1972), 3-13.

7. D.L. Klarstrom, "Thermomechanical processing of Haynes alloy no. 188 sheet to improve creep strength" (Paper presented at Superalloys 1980 Fourth International Symposium on Superalloys, Seven Springs Mountain Resort, Champion, PA, 21-25 September 1980) 131-140.

8. $\quad$ R.L. Dreshfield, "Long time creep rupture of Haynes alloy 188” (Paper presented at Eighth International Symposium on Superalloys, 22-26 September 1996), 383-389.

9. G. Palumbo, Metal alloys having improved resistance to intergranular stress corrosion cracking. U.S. Patent 5,817,193, 1998.

10. W.E. King and A.J. Schwartz, "Toward optimization of the grain boundary character distribution in OFE copper," Scripta Mater. 38 (3) (1998), 449-455.

11. E.M. Lehockey, G. Palumbo, and P. Lin, "Improving the weldability and service performance of nickel- and iron-based superalloys by grain boundary engineering," Metall. Mater. Trans. A, 29 (1998), 3069-79.

12. B. Alexandreanu, B.M. Capell, and G. Was, "Combined effect of special grain boundaries and grain boundary carbides on IGSCC,” Mater. Sci. Eng., 300A (2001), 94-104.

13. E.M. Lehockey et al., "On the relationship between grain boundary character distribution and intergranular corrosion,” Scripta Mater., 36 (10) (1997), 1211-18.

14. C. Cheung, U. Erb, and G. Palumbo, “Applications of grain boundary engineering concepts to alleviate intergranular cracking in alloys 600 and 690," Mater. Sci. Eng., 185A (1994), 39-43.

15. G. Palumbo and K.T. Aust, "Special Properties of $\Sigma$ Grain Boundaries,” Materials Interfaces: Atomic Level Structure and Properties, ed. D. Wolf and S. Yip, (New York: Chapman and Hall, 1989), 190-211.

16. G. Palumbo, E.M. Lehockey and P. Lin, "Applications for grain boundary engineered materials," J. Met., 50 (10) (1998), 40-43.

17. P. Lin et al., "Influence of grain boundary character distribution on sensitization and intergranular corrosion of alloy 600,” Scripta Mater., 33 (9) (1995), 1387-1392.

18. G.S. Was, V. Thaveeprungsriporn, and D.C. Crawford, "Grain boundary misorientation effects on creep and cracking in Ni-based alloys,” J. Met., 50 (2) (1998), 4449.

19. V. Thaveeprungsriporn, and G. Was, "The role of coincidence-site-lattice boundaries in creep of $\mathrm{Ni}-16 \mathrm{Cr}$ -
9-Fe at $36^{\circ} \mathrm{C}, "$ Metall. Mater. Trans. A, 28 (1997), 2101-2112.

20. G. Palumbo and K.T. Aust, "Structure-dependence of intergranular corrosion in high purity nickel," Acta Metall. Mater., 38 (11) (1990), 2343-2352.

21. E.M. Lehockey and G. Palumbo, "On the creep behavior of grain boundary engineered nickel,” Mater. Sci. Eng., 237A (1997), 168-172.

22. V.R. Dave et al., "Grain boundary character in alloy 690 and ductility-dip cracking susceptibility," Welding Journal, 2004, American Welding Society and Welding Research Council, 1-S to 5-S.

23. C.J. Boehlert, D.S. Dickmann, and N.C. Eisinger, "The effect of sheet processing on the microstructure, tensile, creep behavior of INCONEL alloy 718,” Metall. Mater. Trans. A, 37 (1) (2006), 27-40.

24. U. Krupp et al., "The effect of grain-boundaryengineering-type processing on oxygen-induced cracking of IN718,” Mater. Sci. Eng., A349 (2003), 213-217.

25. U. Krupp et al., "Brittle intergranular facture of a Nibase superalloy at high temperature by dynamic embrittlement,” Mater. Sci. Eng., 387-389A (2004), 409-413.

26. T. Watanabe, "An approach to grain boundary design for strong and ductile polycrystals," Res Mech., 11 (1) (1984), 47-84.

27. M. Kumar, W.E. King, and A.J. Schwartz, "Modifications in the microstructural topology in FCC materials with thermomechanical processing," Acta Mater., 48 (2000), 2081-2091.

28. C.B. Thomson, and V. Randle, "The effects of strain annealing on grain boundaries and secure triple junctions in nickel 200,” J. Mater. Sci. 32 (7) (1997), 1909-1914.

29. D.G. Brandon, "The structure of high-angle grain boundaries,” Acta Metall., 14 (11) (1966), 1479-1484.

30. J.E. Hilliard, Met. Prog., 78 (1964), 99-100.

31. Standard Test Methods for Determining Average Grain Size, ASTM Designation E112-96e3, American Society for Testing and Materials, West Conshohocken, PA.

32. E.S. McGarrity, P.M. Duxbury, and E.A. Holm, "Statistical physics of grain-boundary engineering," Phys. Rev. E, 71 (2) (2005), Art. No. 026102 Part 2.

33. C.J. Boehlert, S.C. Longanbach, and T.R. Bieler, "The effect of thermomechanical processing on the creep behavior of Udimet alloy 188,” Philos. Mag., 88 (5) (2008), 641-664.

34. C.J. Boehlert et al., "The evolution of grain-boundary cracking evaluated through in-situ tensile-creep testing of Udimet alloy 188”, J. Mater. Res., 23 (2) (2008), 500-506. 